\title{
La pobreza estructural en las "Bases para el plan de nación"
}

\section{Introducción}

A mediados de enero de 1998, la Comisión Nacional de Desarrollo puso en manos del Presidente de la República, Armando Calderón Sol, el documento Bases para el plan de nación, el cual —con el trabajo del Grupo Gestor, nombrado para promover la consulta y el debate sobre el mismo- ya ha comenzado a ser discutido por los diversos sectores sociales.

El objetivo de tales consultas parte de un supuesto: las Bases para el plan de nación no son algo definitivo y acabado; más bien, constituyen un punto de partida para avanzar hacia la formulación de un Plan de nación que en verdad sea tal; es decir, de una estrategia de desarrollo nacional en la cual un crecimiento económico autosostenido sea coherente con la equidad social, la participación ciudadana y la democracia. Esta es una meta a mediano y largo plazo, a la cual sólo se arribará tras un proceso de evaluación y afinamiento (o corrección) de las ideas contenidas en el documento.

Dada la trascendencia del documento, es de una gran importancia someterlo a las más diversas evaluaciones. Es necesario que en las comunidades, los centros de trabajo, las escuelas, los sindicatos... se sometan a un escrutinio minucioso sus implicaciones prácticas. Ningún sector social debería privarse del derecho de manifestar su palabra sobre las Bases para el plan de nación; pero, para ello, es necesario no sólo tener a mano el documento que las contiene sino examinarlo con el mayor detenimiento.

Dicho documento debe ser leído y meditado con la mayor atención posible por todos los habitantes jóvenes y adultos de El Salvador. ¿Cómo responden las

* Maestro en Ciencias Sociales por la FLACSO-México, Director del Centro de Información, Documentación y Apoyo a la Investigación (CIDAl) de la UCA. 
Bases para el plan de nación a la problemática de mi cantón o caserfo? ¿Cómo se beneficiará la escuela de mi comunidad con las Bases...? ¿Cuáles son los compromisos que las mismas me plantean como trabajador, estudiante o ama de casa? ¿Responden a las necesidades más urgentes del sector social al que pertenezco? ¿Qué es lo que siendo importante queda fuera en ellas? ¿Que es lo que está mal planteado? ¿Qué cosas habría que añadir?

Las anteriores son sólo algunas de las inquietudes que debería suscitar un documento que pretende contar con la participación de lodos los salvadoreños para llevarse a la práctica con éxito. Entre más vacíos se le detecten mejor va a estar cumpliendo su objetivo: ser una propuesta provisional para avanzar - tras intensas discusiones y revisiones - hacia una formulación más acabada de lo que deben ser los derroteros de El Salvador en los planos económico, político, social y ambiental. Ello a sabiendas de que el valor del documento ciertamente está, ante todo, en abrir un espacio a la discusión pública $-y$ no restringida como siempre suele suceder en los círculos de poder- de los problemas nacionales.

Los fracasos o aciertos del documento en su formulación inicial son algo secundario respecto de su principal logro: desencadenar un proceso de discusión social acerca de los principales problemas del país. Sólo después de una evaluación exhaustiva y crítica de las Bases para el plan de nación sabremos cuáles contenidos fueron atinados y cuáles no.

Hacer que todos nos involucremos en esa evaluación y crítica, con honestidad y teniendo como meta el bien de El Salvador, no es un logro despreciable; el documento apunta a este propósito y depende de todos los sectores sociales, económicos y políticos llevarlo a buen término.

La sociedad civil no puede quedar al margen de la discusión del documento. Este es un eje de su evaluación. También es importante examinar sus supuestos teóricos de fondo. Precisamente, ese es el objetivo de las presentes notas. Las preguntas que orientan el artículo son las siguientes: ¿cuál es la idea de pobreza estructural que se tiene en el documento Bases para el plan de nación? ¿Cuáles son las limitaciones conceptuales de la misma? ¿Cuál es su consistencia ante la realidad nacional? Su respuesta $\longrightarrow$ intento de respuesta - es lo que sigue a continuación, habida cuenta que se trata solamente de una modesta contribución al debate sobre el documento elaborado por la Comisión Nacional de Desarrollo.

\section{Sociedad ideal y sociedad real}

Desde tiempos inmemoriales, la construcción de una nueva sociedad ha sido una de las aspiraciones más hondas de la humanidad. No es de extrañar, pues, que la Comisión Nacional de Desarrollo se haya planteado de nueva cuenta ese reto. Como proyecto, una nueva sociedad sólo tiene sentido si rechaza lo exis- 
tente, sino en todas sus dimensiones, sí en aquellas que contradicen más abiertamente lo nuevo que se pretende edificar.

En el documento nos las habemos con tres cosas: (a) la sociedad ideal; $(b)$ la sociedad real, y $(c)$ el problema de la realización del ideal. Cada uno de esos aspectos encierra dificultades intrínsecas a la hora de delimitar su contenido. Porque, ¿cuáles son los elementos necesarios y suficientes para caracterizar a la sociedad ideal? Indudablemente siempre se correrá el riesgo de dejar cosas importantes fuera del ideal o, por el contrario, de introducir en el mismo más de lo debido. ¿Cuáles son las notas que permiten determinar lo que es la sociedad real? Sin duda alguna se puede optar por una fenomenología de la sociedad con el riesgo de perder profundidad explicativa; también se puede buscar lo esencial pero, ¿qué es lo esencial en la sociedad?: ¿la economía, la política o la cultura? ¿O la mutua imbricación de esas instancias? No es fácil ponerse de acuerdo sobre estos temas cuya implicación política dificulta más el análisis.

Pero, en el supuesto de que tuviéramos un ideal de sociedad razonablemente aceptable y que tuviéramos un diagnóstico también razonablemente aceptable de la realidad nacional, ¿cómo hacer que el ideal se realice? ¿Cómo transformar la realidad factual siguiendo los lineamientos planteados por el modelo ideal? Ese tránsito no es automático, no sólo porque entre lo ideal y su realización existen mediaciones que pueden desdibujar los propósitos del primero, sino también porque la realidad factual posee dinamismos propios que hacen resistencia a su transformación.

Las tres problemáticas que hemos apuntado están presentes en las Bases para el plan de nación. En ellas hay un ideal de sociedad; un diagnostico de la sociedad realmente existente y unos lineamientos para hacer que esta última sea transformada a la luz de aquel ideal. Dado que la realización del ideal de sociedad excede los límites formales del documento - y su valoración sólo puede tener sentido una vez que ese proceso de realización se haya iniciado y, más aún, haya rendido sus primeros frutos-, aquí nos ocuparemos esencialmente de un tema crucial en el escrito $-y$, por supuesto, en el momento actual de El Salvador: la pobreza estructural. El mismo lo analizaremos en el marco del diagnóstico social presente en las Bases para el plan de nación.

\section{El diagnóstico social}

\subsection{Ambitos de la realidad social}

Una lectura atenta de las Bases para el plan de nación nos lleva a la siguiente conclusión: la sociedad salvadoreña adolece de graves males, cuya importancia guarda relación estrecha con la jerarquía asignada a cada una de las instancias que constituyen a la sociedad. 
Para la Comisión Nacional de Desarrollo, la sociedad no es una realidad imprecisa o un todo uniforme; es, por el contrario, una realidad compuesta por varios niveles o dimensiones. Estos niveles o dimensiones son los siguientes: economía, cultura, política, medio ambiente y familia. A lo largo del documento -y específicamente en su capítulo V: "Lo que el pals necesita"- es recurrente la referencia a esas dimensiones de la sociedad.

No queda suficientemente claro, sin embargo, cómo es que las mismas se articulan. Y el vacio no es intrascendente. Si se asume que en la dinámica social la economía es lo más relevante - aun sin llegar a afirmar que es lo determinante en última instancia-, la jerarquía (y la valoración) que se dé a los problemas sociales será distinta de si se asume que lo más relevante es la cultura o la política.

Si se acepta que la familia es el núcleo de la sociedad -es decir, el centro en torno al cual todo lo demás gira- se pondrán de relieve aspectos sociales que posiblemente pasen a segundo plano si en lugar de aceptar a la familia, se asume a la empresa (al mundo del trabajo) como eje de la sociedad. Lo mismo cabe decir del medio ambiente: éste se puede considerar como una "variable externa" para la reproducción social -como se hace en los enfoques tradicionales-, o se lo puede considerar como la condición sine que non de la viabilidad social. Y cada una de las perspectivas que se asuma aportará énfasis distintos sobre los problemas de la sociedad.

Las Bases para el plan de nación destacan claramente los principales ámbitos de la realidad social (economía, cultura, política, medio ambiente y familia), pero no dejan claramente establecido el tipo de relación que guardan entre sí, ni si uno de esos ámbitos es el más importante o lo son todos por igual. Hay una propensión a dotar a la cultura (lo sociocultural) de un papel preponderante en la dinámica social; sin embargo, no se encuentra en el documento un tratamiento explícito del tema, por lo que sería bastante arriesgado adscribir al paradigma de la modernización la elaboración de la Comisión Nacional de Desartollo.

Es pertinente traer a cuenta que en la perspectiva de la modernización - tal como, por ejemplo, la expuso el sociólogo Gino Germani' -, los cambios sociales son, en el fondo, cambios culturales, es decir, cambios en los valores, las creencias y las opciones de los individuos. En consecuencia, la cultura es el eje de la vida social; la fuente última de los problemas sociales y el ámbito en el cual se tienen que efectuar las transformaciones necesarias del orden social. Después del cambio cultural viene el cambio político y el cambio económico². Por lo demás, esa "visión modernizadora" es francamente notoria en la Propuestạ de reforma educativa elaborada por la Comisión Nacional de Educación, Ciencia y Desarrollo, dos de cuyos miembros integraron la comisión que elaboró las Bases para el plan de nación's. 
Por otra parte, en el documento de la Comisión Nacional de Desarrollo se aborda el "nudo crucial de nuestra problemática", esto es, aquello que está en la base de los graves problemas sociales en el momento actual de El Salvador. Textualmente, las Bases lo plantean asf: "aunque la realidad por su propia naturaleza es compleja y sus componentes tienen expresiones muy variadas, siempre hay un nudo gordiano que determina el resto de la problemática. En El Salvador ese nudo gordiano es la pobreza estructural"4.

Tomado a la ligera, probablemente no se caiga en la cuenta del alcance de la afirmación. Pensada más detenidamente, la misma apunta a algo grave y, además, complejo. No se está hablando de cualquier cosa, sino de la pobreza, ese núcleo duro de la realidad social salvadoreña de cuyas múltiples y variadas manifestaciones todavía sabemos poco.

Pobreza urbana, pobreza rural, pobreza extrema, pobreza absoluta, pobreza relativa.... Son tantas las pobrezas que existen que, si bien encasillarlas en aquello que les es común puede facilitar la discusión, en nada la enriquece ni permite avanzar analíticamente en el conocimiento de la realidad social. Como todas las macrocalegorías —otras del mismo estilo son las palabras "pueblo", "masas", "clase social", "proletariado", "estructura"- la palabra "pobreza" dice mucho pero no explica nada. pues engloba en una sola expresión las varias pobrezas existentes sobre las cuales hay que investigar y discernir conceptualmentes.

Pero, además, el nudo de los problemas sociales en El Salvador no es la pobreza sin más, sino la pobreza estructural. Con ello aparece en la discusión un concepto en sí mismo problemático: el concepto de estructura. Aceptar que la realidad social es estructural supone: (a) tener claridad sobre las instancias que la constituyen, $(b)$ sobre la articulación que existe entre ellas y $(c)$ sobre el tipo de unidad que caracteriza a la estructura social. En torno al primer punto, las Bases... no dejan dudas; en torno a los otros dos, el rigor que exige un análisis estructural está ausente. Con todo. si se deja de lado esta consideración —demasiado filosófica para más de alguno-, no se puede dejar de prestar atención a la idea de que en El Salvador es la pobreza estructural la que determina el resto de los problemas sociales.

\subsection{Pobreza estructural y marginación sociocultural}

De entrada, la afírmación citada en el párrafo anterior parece aguda y valiente. Pero, $\iota^{a}$ qué se refiere la Comisión Nacional de Desarrollo cuando habla de pobreza estructural? Obviamente se nos quiere decir que la pobreza no es algo accidental y pasajero, sino una realidad honda y permanente, inscrita en la constitución de sociedad salvadoreña. La consecuencia que se sigue de esa tesis es que en la actual configuración social del país la pobreza no puede ser superada o alterada significativamente, puesto que ello introducirfa un carnbio en la estructura social establecida. 
¿Y si queremos combatir o. Inejor aún, erradicar la pobreza? Hay que apostarle al cambio estructural. La Comisión Nacional de Desarrollo no da ese paso, que. sin duda alguna, la hubiera llevado por un sendero distinto: aquél que apuntaría a la necesidad de iransformaciones en el acceso a la propiedad y la riqueza.

El escollo se salva justamente introduciendo otro elemento en la discusión: lo sociocultural. Según el hilo de la argumentación que veníamos siguiendo, la pobreza estructural era el nudo gordiano que determinaba todas las otras problemáticas del país, las cuales en definitiva sólo podían ser enfrentadas con medidas de carácter estructural.

La pobreza estructural, hasta este momento, era el punto de partida hacia otros niveles de la realidad. De pronto nos encontramos con que no era ella el punto de partida sino la consecuencia de algo más profundo. "Hay que aclarar, sin embargo - se lee en el documento-, que dicha pobreza, aunque se vuelve causa de otros múltiples efectos políticos, socioeconómicos y culturales, se asienta en una realidad aún más prolunda: la marginación sociocultural".

Dejando de lado lo confuso de la frase -lo socioeconómico y cultural es efecto de la pobreza estructural y, a la vez, la pobreza estructural es resultado de lo sociocultural - y dejando de lado la ruptura que se produce con la misma en el proceso argumentativo precedente, la nueva tesis es, sino insostenible, absolutamente discutible.

Ante todo, ¿qué se entiende por marginación sociocultural? Eso no está claro en el documento. ¿Se trata acaso de un marginación a la que se ven sometidos individuos y grupos por las creencias y valores que proclaman? $\mathrm{Y}$ si esto se responde positivamente, ¿dónde están esos grupos y cuáles son esos valores y creencias que los colocan en la marginalidad y los condenan a la pobreza?

Siendo rigurosos, ni siquiera de las "maras" (con sus tatuajes, grafitis y singular vestimenta) se puede afirmar tajantemente que son excluidas de la vida económica del país en virtud del rechazo cultural a que se ven sometidas por las personas "normales", sino todo lo contrario: la pertenencia de la mayoria de sus miembros a familias pobres (no necesariamente en la extrema pobreza) y desintegradas por el alcholismo y la drogadicción han sido factores decisivos para oplar por un estilo de vida situado en la marginalidad, el cual, a su vez, repercute sobre las condiciones socioeconómicas que le dieron origen.

Hay, pues, en el caso de las "maras", una circularidad que no puede ser soslayada: pobreza y precariedad afectiva de los hogares en que nacen la gran mayoría de sus miembros $\rightarrow$ marginalidad sociocultural ("maras") $\rightarrow$ agudización de la situación de pobreza (con superación de la precariedad afectiva). Esta circularidad es la que hace demasiado simplista la afirmación de que las "maras" viven en la marginalidad sociocultural porque provienen de familias 
pobres y desintegradas; asimismo, hace que la afirmación inversa -que quienes conforman las "maras" viven en hogares pobres y desintegrados como consecuencia de esa adscripción sociocultural' — tampoco sea del todo atinada .

Pero dejando de lado el caso de las "maras" — del cual, por lo demás, sabemos poco todavía- en El Salvador no es fácil encontrar grupos sociales significativos que sean rechazados en el trabajo, la escuela o la burocracia estatal por los patrones culturales (religiosos, artísticos, éticos o morales) que proclamen, en cuanto que se consideran radicalmente distintos y excluyentes de los demás grupos sociales. Los dos grandes ejes de la marginalidad sociocultural de todos los tiempos - la raza y la religión y sus contrapartidas la persecución étnica y la persecución religiosa- no existen hoy por hoy en El Salvador. De aqu' que sostener que ella es la luente de la pobreza estructural y de todos los problemas que se derivan de la misma es algo que no tiene asidero en la realidad.

Sin irnos a los extremos, la marginalidad sociocultural se puede entender en un tono menor: lo inaccesible que son para la mayoría de salvadoreños tanto los bienes culturales y públicos más sofisticados (arte especializado, medicina especializada) como los bienes culturales y públicos menos sofisticados (educación básica, literatura nacional, servicios sanitarios básicos).

Ciertamente, en su gran mayoría, la población del país está marginada del acceso a estos bienes. Pero esa marginación no es un hecho inicial sino un punto de llegada; es decir, es consecuencia de la situación de pobreza en la que vive la mayoría de salvadoreños. Y aquí también se genera un círculo vicioso: el no poder acceder, en razón de la precariedad económica, a bienes culturales y públicos básicos agudiza la situación de pobreza de la mayor parte de la población. Pero el factor generador de esa marginalidad es la precariedad económica — se le puede denominar "pobreza estructural" para estar en sintonía con el documento de la Comisión Nacional de Desarrollo- que afecta a más del 50 por ciento de los hogares salvadoreños.

En resumen, la tesis de una relación de causalidad entre la marginalidad sociocultural (variable independiente) y la pobreza estructural y sus derivados (variable dependiente) es desde todo punto de vista insostenible. Conceptual y empíricamente hubiese tenido más viabilidad explorar la relación inversa.

\section{Poder político tradicional}

Ahora bien, la inconsistencia lógica de las Bases... no se agota en el anterior punto, sino que se continúa en un siguiente argumento, como veremos enseguida. En efecto, en el documento se nos dice que "tal marginación (sociocultural) que está presente en todos los aspectos de la vida y de la relación entre nosotros, deriva a su vez de la configuración y el funcionamiento tradicional del poder politico" . La confusión conceptual y la falta de coherencia saltan a la vista. 
La marginación sociocultural considerada hasta este momento como la raíz última de todos los problemas sociales - porque es la que genera la pobreza estructural-, de pronto ha dejado de ser lo más importante porque ella misma deriva de otro aspecto (¿más fundamental?): el funcionamiento tradicional del poder político.

Así, puestas las cosas en orden, tenemos que la secuencia analítica-causal pobreza estructural $\rightarrow$ problemas sociales, económicos, culturales y políticos no es la adecuada; tampoco lo es la secuencia marginación socioculitural $\rightarrow$ pobre$z a$ estructural $\rightarrow$ problemas sociales. La secuencia correcta es la siguiente: poder político tradicional $\rightarrow$ marginación sociocultural $\rightarrow$ pobreza estructural.

Si la introducción de lo sociocultural como factor causal es más que discutible, la entrada en escena del poder político tradicional constituye un franco desatino: es imposible defender con un mínimo de racionalidad la idea de que la raiz de los problemas sociales (pobreza, marginalidad sociocultural, etc.) sea la política tradicional.

Por si fuera poco, en el documento no se da la mínima explicación de cómo sucede eso. La razón de ello es simple: no hay modo de vincular causalmente el impacto del poder político tradicional sobre la pobreza estructural y los problemas sociales que se derivan de la misma. Y ello porque se trata de órdenes de realidad distintos, cuya relación es más bien de carácter funcional.

Crisis de legitimidad, incredibilidad política, autoritarismo, resistencia al imperio de la legalidad... Estos sí que son problemas que se explican por la vigencia del poder polf́tico tradicional (y sus secuelas), y son problemas cuya solución se ha iniciado con la "cirugía en las estructuras del poder político" propiciada con los acuerdos de paz, con los cuales se ha creado un nuevo escenario "para el despliegue de la democracia en el país"y.

Indudablemente, el saneamiento del poder político prepara el terreno para el despliegue de la democracia política, pero la vigencia de la democracia política no supone automáticamente la vigencia de una democracia social, que es justamente donde se juega el combate de la pobreza estructural y sus derivados.

Pueden perfectamente existir la primera sin la segunda, como de hecho ha sucedido en la mayoría de naciones latinoamericanas en el siglo $\mathrm{XX}$. Y ello porque las vías para alcanzar una y otra son distintas: la dernocracia política se consigue básicamente fomentando el pluralismo político e ideológico y las elecciones periódicas (desarticulando los mecanismos autoritarios de poder); la democracia social se obtiene modificando los mecanismos de acceso a la propiedad y la riqueza. La primera puede contribuir a lo segundo, pero su relación no es automática.

El poder político tradicional ha sido fuente de muchos males en El Salvador del siglo XX. Desarticular su mecanismos de funcionamiento es una tarea en sf 
misma importante. Este era uno de los principales propósitos de los acuerdos de paz.

Ahora bien, la reforma política del poder político tradicional es necesaria no porque éste sea generador de la pobreza, sino porque a su sombra y protección se incubaron una estructuras de propiedad a las cuales les es consustancial el empobrecimento de los salvadoreños. Es decir, el poder político tradicional estuvo en función de un esquema de concentración de la riqueza (todavía vigente en muchos aspectos) que deja a la mayoría de los habitantes del país en una situación de miseria extrema. Más aún, el poder político no sólo amparaba a los grupos de poder económico, sino que ponía en marcha su maquinaria represiva cada vez que aparecía en escena un intento de reformar el sistema de propiedad establecido.

En el marco de estas consideraciones adquiere sentido plantearse la desarticulación del poder político tradicional como requisito ineludible para avanzar hacia la solución del problema de la pobreza estructural. No porque sea su causa, sino porque a lo largo del siglo $\mathrm{XX}$ estuvo en función de un sistema de propiedad y de acceso a la riqueza generador de miseria y pobreza. Era este el sentido de la reforma política propiciada con los acuerdos de paz: alcanzada la democracia política iba a ser posible dar inicio a la reformas económicas necesarias para combatir la pobreza. Esta problemática fue recogida por los acuerdos de paz con una claridad y coherencia lógica ausentes totalmente en las Bases para el plan de nación.

\section{Reflexión final}

El diagnóstico de la realidad social salvadoreña presente en las Bases para el plan de nación, si bien es cierto arranca de la constatación de que la pobreza estructural es el principal foco de los problemas sociales en el país, en seguida renuncia a esa constatación y a sus implicaciones al retrotraer las causas de los problemas sociales - la pobreza estructural incluida- a factores socioculturales y, más en el fondo, a factores políticos.

De este modo, la lógica inicial se invierte y lo que aparecía como causa termina siendo un efecto. La inversión causal operada por la Comisión Nacional de Desarrollo hace que su diagnóstico termine por perder de vista no sólo la centralidad que tiene la pobreza en la dinámica social del pafs, sino los factores estructurales que la generan, los cuales se hayan afincados en el sistema económico vigente.

El diagnóstico social presente en el documento que analizamos, además de no resistir el contraste con la realidad nacional, está plagado de incoherencias lógicas y de ideas confusas y sin desarrollar. Se trata de un diagnóstico cuya etiologfa o bien busca en los síntomas la causa de la enfermedad o bien atribuye 
los síntomas de una enfermedad a otra. En ambos casos, las recetas terminarán convirtiéndose en un disparate.

\section{Notas}

1. Ver Gino Germani, Sociedad y política en una época de transición, Buenos Aires, Paidós, 1963.

2. Ver Francisco Zapata, Ideología y políica en América Latina, México, El Colegio de México, 1990.

3. En la primera comisión esluvieron Gilberto Aguilar Aviless, Luis Cardenal, Francisco Castro Fuentes, David Escobar Galindo, Norma Fidelia Guevara, Héctor Lindo, Roberto Palomo, Gregorio Rosa Chávez, Joaquín Samayoa, José Eduardo Sancho, Sandra Rebeca Vázquez de Barraza y Knut Walter. En la segunda, estuvieron Sandra Rebeca Vázquez de Barraza, Roberto Rubio, Francisco R.R. de Sola, Salvador Samayoa, David Escobar Galindo y Abelardo Torres. Sobre la propuesta educativa, ver Luis Armando González y Angel Sermeño, "Análisis sociológico de la propuesta de la Comisión Nacional de Educación, Ciencia y Desarrollo", ECA, No. 561-562, julioagosto de 1995, pp. 635-655.

4. Bases.... p. 5.

5. Ver Renete Schubert, "La pobreza en los paises en desarrolio: concepto, magnitud y consecuencias", Contribuciones. No. 3, 1995, pp. 7-32.

6. Bases... p. 5

7. Ver Instituto Universitario de Opinión Pública (IUDOP), "Solidaridad y violencia. Los jóvenes pandilleros en el Gran San Salvador", ECA, No. 585-586, julio-agosto de 1997, pp. 695-710.

8. Bases... p. 5.

9. Bases...p. 5. 